\title{
Critical Thinking for Engineers and Engineering Critical Thinking
}

\author{
Tim Kenyon \\ Department of Philosophy, \\ University of Waterloo \\ Waterloo, Ontario \\ Canada N2L 3G1 \\ tkenyon@uwaterloo.ca
}

\begin{abstract}
Design decisions for a critical thinking curriculum for Engineering students serves as a point of departure to briefly describe an under-appreciated reason to emphasize critical thinking in Engineering programs. An increasing focus on the role of context, environment and systems in shaping human judgement means that engineers should be especially aware of the propensity for designs and implementations to affect the reasoning of people for whom they function as lived experience. Preparing engineers to recognize and work responsibly around these issues is a secondary reason to teach critical thinking in those programs.)
\end{abstract}

Keywords—critical thinking; nudges; engineering; debiasing; pedagogy

\section{INTRODUCTION}

The benefits of teaching critical thinking skills to Engineering students are, at first glance, essentially the same as the benefits of teaching critical thinking skills to any kind of student. The virtues of "self-guided, self-disciplined thinking," as Scriven \& Paul [12] define critical thinking, or of students "skillfully taking charge of the structures inherent in thinking and imposing intellectual standards upon them," as Paul \& Elder [5] suggest, seem to be unspecific to discipline. At the same time, one need not endorse the recent and muchdiscussed Gambetta \& Hertog's [7] thesis that engineers are peculiarly susceptible to radicalization via simplified mechanistic and hierarchical reasoning in order to think that some disciplinary differences might be relevant to how critical thinking is and ought to be taught.

The 'is' and 'ought to be' distinction here is not trivial. It is the practically universal conceit of every discipline, every course, every instructor, that what they teach already incorporates critical thinking. And the notion of critical thinking itself is sufficiently undefined to indulge this happy thought, to some degree. Nevertheless, the way critical thinking is most intuitively taught in a discipline might not be a way that generates the greatest benefits for students. Teaching critical thinking to literature students chiefly as a kind of linguistic rhetorical analysis might seem natural in that context; but to neglect the respects in which critical reasoning requires

This work was supported by the Faculty of Arts, University of Waterloo, and by the Social Sciences and Humanities Council of Canada. certain kinds of numeracy is to do students a disservice. Similarly, the disposition to reduce critical thinking to the straightforward application of fixed rules, or to some sort of algorithmic progression through problem-solving stages, might fit well with disciplinary norms common within Engineering (for an example, consider Tran in [14]), without very seriously addressing key critical thinking skills such as dealing with ambiguity, reasoning from assumptions that do not remain fixed, or deploying guidelines that are inconsistent in some contexts.

My aims in the following brief position paper are, first, to sketch one curricular approach to teaching critical thinking in an Engineering context that links a less rule-based approach to some of the norms that animate professional engineering education; and second, to emphasize how that approach itself might be broadened. Specifically, I suggest that increasing evidence regarding the role of the physical and socioinstitutional reasoning context in cogent judgement has implications for importance of teaching critical thinking in Engineering programs: the professionals involved in engineering our lived environments should understand how their work can impact the judgements of clients and end users of engineered applications, solutions and designs.

\section{CRITICAL THINKING FOR ENGINEERS}

In 2010 I was the curricular lead on a professional development course for Engineering undergraduate students.

In essence PD20 is a course on critical thinking in the workplace. In particular the objective of the course is to help engineering students that are new to the professional workplace make objective observations on all aspects of their workplace activity, draw logical conclusions from their observations, and communicate their findings to both lay and technical audiences. [1]

The course was solicited to replace an existing but intensely unpopular course developed "by committee," internal to the program. That course, plausibly, reflected the assumption already mentioned: that what everyone teaches counts as critical thinking. Thus, without any single contributor intending this, the designers in aggregate employed a patchwork of specialized topics rather than a focused approach that emphasized outcomes and alignment.

By bringing in critical thinking instructors from outside the field of Engineering, the redesign invited a more unified and less discipline-specific conception of what critical thinking could comprise. But this also invited potential dissatisfaction on the part of students with any curriculum perceived as ungrounded in Engineering norms and needs. To forestall this 
concern, the design of the course made particular efforts to link so-called "soft skills" of critical thinking as directly as possible to the professional demands of a successful Engineering career, whether in practice or in research.

The course design emphasized "epistemic humility: recognizing situations in which one does not possess the right quality or quantity of information; being willing to admit this (to oneself, not least); and taking constructive steps to address the problem by marshalling evidence, constructing wellreasoned cases, and sharing solutions as appropriate." But it did so by linking these skills and attitudes to concrete and discipline-specific goals. As the submitted curriculum proposal noted,

[s]tudents are encouraged to be both aware of and comfortable with the very common circumstance of having incomplete, imperfect or ambiguous information. This is a crucial first step in the process of improving one's state of information and collaborating as an informed team member in the workplace. Engineering students who are insensitive to their own knowledge deficits, or who are unwilling to admit ignorance, are not just more prone to reasoning errors they are also less open to the spontaneous and opportunistic learning that characterizes most postgraduation (and much pre-graduation) knowledge acquisition and professional development. They may also show deficits in workplace socialization, ethics, and collegiality if they do not develop the habit of reflectively holding their own attitudes and behaviour at arm's length to appreciate their effects on colleagues, clients, and others. Thinking diagnostically, being self-aware, and communicating clearly in these contexts are therefore essential to a successful and enjoyable work life.

The learning outcomes were explicitly anchored in disciplinary and professional norms through the recruitment of working researchers and practitioners to deliver brief anecdotes on video - one per course unit - explaining how a notable failure or success in their experience arose from a deficit or the effective use of the particular critical thinking skill.

In practice, this appears to have been an effective approach. Students have been consistently open to seeing fundamentally social, ethical, or emotional skills, like admitting error or counteracting gender bias, defended as essential Engineering skills by exemplars within the discipline. And while this critical thinking course also imparts knowledge and skills of formal reasoning and logic, it has succeeded also in engaging Engineering students in methods, skills and dispositions that might otherwise be devalued as characteristic of humanities or otherwise non-scientific fields.

\section{ENGINEERING CRITICAL THINKING}

Under a new curriculum designer, this course has since been tweaked (and no doubt improved) in the interim. But the description provided here is sufficient for use as a point of departure for the further, and in some respects more radical, line of thought that follows. My reflective assessment of the approach to critical thinking for Engineers that I have sketched here is, in retrospect, not that it is mistaken, but that it is incomplete in at least one important respect.

That respect comes into sharper relief if we consider a recently influential conception of effective reasoning that broadens the notion of critical thinking further still. This approach takes a cue from an account of human judgement that emphasizes the role of physical and social infrastructure in creating so-called nudges or choice architectures [14]. But it refines this idea to focus more specifically on critical thinking contexts and infrastructure, and their potential role in generating truth-conducive debiased (or in any case lessbiased) reasoning. This move is based on empirical evidence indicating that the reasoning strategies likeliest to be effective at reducing distortions are also quite difficult to implement as an individual or lone reasoner [6], [10], [9], [2]. But with contextual supports of various kinds, these strategies are apt to be more accessible and effective. What's wanted, then, is a notion of critical thinking that includes such measures.

\section{Thus Guillaume Beaulac and I have proposed}

...to broaden the conception of what counts as promoting critical thinking, a suggestion that we take to be both more consistent with the ways that reasoning and decisions are generally regarded as successful or virtuous, and more promising from an educational perspective. We will summarize our broadening taxonomy in the following remarks, but at a first pass the idea is to include contextual, social, institutional, and physical infrastructure among the range of correctives to distortive reasoning. This approach means that education devoted to teaching both the value of such infrastructures, and the methods of constructing and appropriately deferring to it, is properly seen as critical thinking education as well. In effect we proposed both a more inclusive and a finergrained taxonomy of cases, corrections, strategies, and educational options. More things, and more effective things, count as critical thinking on this view [2].

Inasmuch as cogent reasoning is facilitated by particular kinds of contextual aids or infrastructure, critical thinking education is reasonably understood to include knowledge and skills of creating, employing, and deferring to such reasoning infrastructure. We can understand this approach most simply by taking some liberties with Thaler \& Sunstein's notion of a "nudge," a designed feature of some process, artifact or situation that is intended to provoke a particular way of reasoning about a topic. Empirical evidence regarding the kinds of reasoning errors that are particularly likely, on a topic, in a context, may be used to help shape such contexts in order to mitigate errors of that kind. Reasoners are "nudged" towards cogent thinking by the designed features of their environments.

We may broaden Thaler \& Sunstein's definition of a nudge to emphasize reasoning effects, and to include socioinstitutional factors. Thus, for example, the idea of placing the salads where they will be encountered first by students entering a school cafeteria, in order to promote healthy eating (a Thaler \& Sunstein example), can be extended to include placing reminders about gender or racial biases first in the agenda of a hiring committee meeting. To the extent that such a process 
represents an informed choice about how to reason well, it seems clearly to be an expression of critical thinking aims. And to the extent that critical thinking education is oriented towards securing such outcomes, the environmental or contextual approach suggests teaching the construction and deployment of such "choice architectures" as critical thinking skills. This approach to critical thinking is receiving increased attention [3], [15], [4]. What remains less appreciated about it, however, is the special significance it bears for the training of engineers.

Any engineering solution to a problem with which people interact, at whatever remove, is a respect in which a design will influence judgements people make relative to that interaction. The question is not whether, but to what extent to and to what effect the built features of physical, digital, functional or procedural design and solutions will impact the capacity and the disposition of people to reason in a context. While this might seem primarily to implicate engineering in sub-fields like Systems Design, the phenomenon is too general to be siloed in this manner. Micro-design features of software, road infrastructure, building structures, and the like will have effects on the lived experience of end users. These effects will no doubt operate in ways that are hard to predict under any circumstances. But they are impossible to plan without some informed awareness of the respects in which thinking itself is responsive to situational and environmental engineering.

Principles of sound design are already fairly widely taught in Engineering programs. Social, institutional, and communicative issues in design problem-solving are matters of some recent scholarly discussion as well [8]. But principles of design engineering are not typically taught as instruments of good reasoning for the end users of the solutions or designs. A consequence of the environmental-inclusive view of critical thinking, I argue, is that this ought to change. The profound effects that engineering has on the world include effects on the contexts within which people reason. Responsible engineering thus includes a duty of care with how these contexts are affected by design treatments and implementations.

As Thaler \& Sunstein argue (in the sole allusion to engineering in [13]),

[t]he more choices there are, and the more complex the situation, the more important it is to have enlightened choice architecture. To produce a user-friendly design, the architect needs to understand how to help humans. Software and building engineers live by a timehonored slogan: keep it simple. And if a building has to be complicated to be functional, then it is best to offer plenty of signs to help people navigate. Choice architects need to incorporate these lessons (p. 174).

Implicit here is the fact that there is no neutrality in reasoning contexts; no null effect. Every context presumably makes some difference or other - via, for example, such factors as the presence or absence of design clutter or forced choices that distract people from reasoning well under stress.

\section{CONCLUSION}

Here, then, are the seeds of a somewhat radical suggestion, with which I will conclude, regarding the value of teaching critical thinking to Engineering students. Engineering students need an especially deep and thorough education in critical thinking, including in its most empirically-informed versions, because they owe a double duty to the norms of sound judgement. First, they must reason cogently themselves in order to be effective practitioners and researchers in their discipline. But as applied scientists and designers of solutions, they must moreover understand the respects in which applications and designs modify the choices and reasoning of other people, of whose lived environments these things are a constitutive element. Engineers need critical thinking not only because engineers need to be critical thinkers, but because they may so easily influence respects in which other people are critical thinkers. How this idea may be incorporated into Engineering curricula and teaching practices is a far more involved question, but one that is, I submit, eminently worth asking.

\section{REFERENCES}

[1] Andres, G., Kenyon, T., Peariso, R., Pretti, J., Stubley, G. (2011.) 'Critical thinking in the workplace: A course design and implementation.' Conference Proceedings of the Canadian Engineering Education Association.

[2] Beaulac, G., \& Kenyon, T. (2016.) The scope of debiasing in the classroom. Topoi. First Online: 30 May 2016. doi:10.1007/s11245-0169398-8

[3] Bonnefon, JF., (2016). The pros and cons of identifying critical thinking with System 2 processing. Topoi. First Online: 26 March 2016. DOI: 10.1007/s11245-016-9375-2

[4] Corriea, V. (2016). Contextual debiasing and critical thinking: Reasons for optimism. Topoi. First Online: 26 April 2016. DOI: 10.1007/s11245016-9388-X

[5] Elder, L., \& Paul, R. (2013). 30 days to better thinking and better living through critical thinking: a guide for improving every aspect of your life (Rev. and expanded [ed.]). Upper Saddle River (NJ): FT Press.

[6] Fischhoff, B. (1982). Debiasing. In D. Kahneman, P. Slovic, and A. Tversky (Eds.), Judgment Under Uncertainty: Heuristics and biases. Cambridge: Cambridge University Press: 422-444.

[7] Gambetta, D., \& Hertog, S. (2016). Engineers of Jihad: The Curious Connection between Violent Extremism and Education. Princeton NJ: Princeton University Press.

[8] Jonassen, D., Strobel, J. and Lee, C. B. (2006), Everyday problem solving in Engineering: Lessons for Engineering educators. Journal of Engineering Education 95: 139-151. doi: 10.1002/j.21689830.2006.tb00885.x

[9] Kenyon, T., \& Beaulac, G., (2014.) Critical thinking education and debiasing. Informal Logic 34 (4): 341-363.

[10] Lilienfeld, S., Ammirati, R., \& Landfield, K. (2009). Giving debiasing away. Perspectives on Psychological Science 4.4: 390-8.

[11] Lord, C.G., Lepper, M.R., Preston, E. (1984). Considering the opposite: A corrective strategy for social judgment. Journal of Personality and Social Psychology, 47(6): 1231-1243.

[12] Scriven, M., \& Paul, R. (1987). Critical thinking as defined by the National Council for Excellence in Critical Thinking. 8th Annual International Conference on Critical Thinking and Education Reform. Online: $\quad<$ http://www.criticalthinking.org/pages/defining-criticalthinking/766>.

[13] Thaler, R. H., \& Sunstein, C. R. (2008). Nudge improving decisions about health, wealth, and happiness. New Haven (CT): Yale University Press.

[14] Tran, M. (2013). Critical thinking for engineers. Electrical and Computer Engineering Design Handbook. https://sites.tufts.edu/eeseniordesignhandbook/2013/an-engineers-pathto-critical-thinking/ (Accessed June 1, 2016.) 
[15] van Geene, K., de Groot, E., Erkelens, C., Zwart, D. (2016). Raising awareness of cognitive biases during diagnostic reasoning. Perspectives on Medical Education 5.3: 182-185.
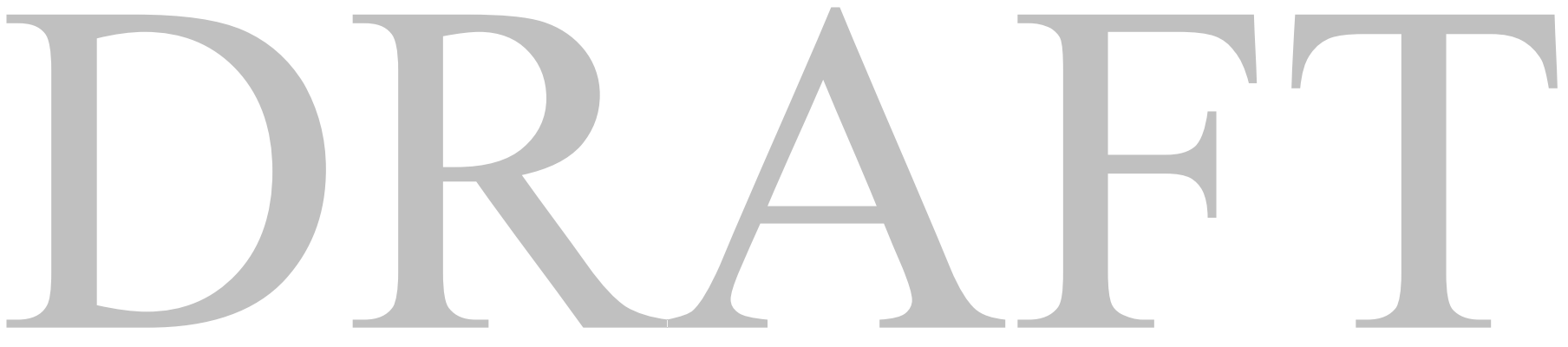